\title{
Analisis Sisa Gajah Dari Kecamatan Tamban, Kabupaten Batola (Kalimantan Selatan): Suatu Pengumuman
}

\section{Rokus Due Awe}

Keywords: Proboscidae; fossils; identification; Borneo

\section{How to Cite:}

Due Awe, R. (1989). Analisis Sisa Gajah Dari Kecamatan Tamban, Kabupaten Batola (Kalimantan Selatan): Suatu Pengumuman. Berkala Arkeologi, 10(2), 21-30. https://doi.org/10.30883/jba.v10i2.541

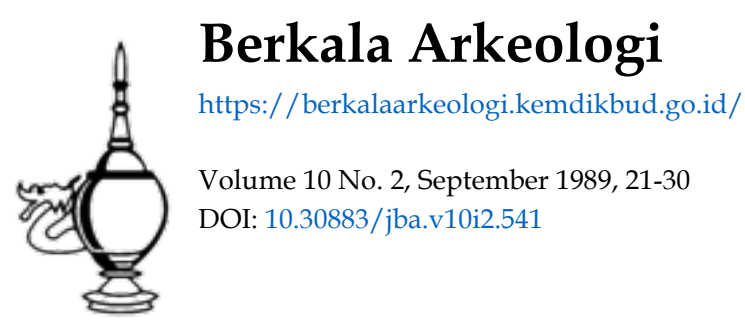




\section{ANALISIS SISA GAJAH DARI KECAMATAN TAMBAN, KABUPATEN BATOLA (KALIMANTAN SELATAN): SUATU PENGUMUMAN \\ Oleh : Rokus Due Awe}

\section{PENDAHNLUAN}

Dalani tahun 1987 Pusat Penelitian Arkeologi Nasional dimirita untuk mengareksi suatu temuan yang baru dilakukan oleh Bidang Pernıuseuman Sejarah dan Purbakala Kantor Wilayah Departemen Pendidikan dan Kebudayaan Propinsi Kalimantan Selatan. Penemuan tersebut dituangkan dalam sebuah laporan yang dilengkapi dengan beberapa buah foto dan denah lokasi penemuan. Di dalam laporan itu diinformasikan bahwa berdasarkan ukuran tulang yang besar-besar, tim yang bersangkutan menyatakan bahwa sisa-sisa binatang fosil yang ditemukan itu berasal dari suatu individu yang disebut sebagai gorila. Setelah dilakukan perıgamatan terhadap foto-foto yang dilampirkan, Pusat Penelitian Arkeologi Nasional mengidentifikasikan sebagai salah satu individu Bangsa Proboscidea (Bangsa berbelalai atau gajah).

Dugaan tersebut terutama didasarkan pada foto yang memperlihatkan fragmen gigi yang di dalam laporan itu disebutkan sebagai "fosil". Untuk membuktikan dugaan tersebut, Pusat Penelitian Arkeologi Nasional minta beberapa potong fragmen "fosil" pada Bidang Permuseuman Sejarah dan Purbakala Kantor Wilayah Departemen Pendidikan dan Kebudayaan Propinsi Kalimantan Selatan.

Dalami bulan Februari 1988 Pusat Penelitian Arkeologi Nasional telah menerima beberapa potong sisa binatang fosil yang ditemukan di Kecamatan Tamban (Kalimantan Selatan). Sisa binatang fosil yang dikirim tersebut terdiri dari satu fragmen geraham dan satu frag- 
men ruas tulang punggung. Dilihat dari bentuk fragmen geraham dan ukuran ruas tulang punggung, sisa binatang fosil yang telah ditemukan di Kecamatan Tamban itu benar-benar berasal dari Bangsa Proboscidea, Marga Elephantidae, Suku Elephas.

Dari hasil analisis terhadap sisa-sisa binatang fosil tersebut, ternyata berasal dari Suku Elephas bukan gorila. Temuan ini yang merupakan data penting, karena selama ini di daerah Kalimantan (wilayah Indonesia) belum pernah ditemukan sisa binatang fosil jenis elephas. Sernentara itu dilaporkan pula adanya temuan sisa Palaeoxodonta (salah satu binatang fosil dari bangsa Proboscidea yang sudah punah) di Kalimantan Timur, di sekitar Balikpapan-Samarindá. Penemuan Palaexodonta tersebut hanya berupa inforniasi karena benda temuarinya sendiri tidak berada di Indonesia. Demikian juga yang terjadi di bagian utara pulau ini. Di sana dilaporkan pernah ditemukan Stegolophodon, salah satu sisa binatang fcsil dari Bangsa Proboscidea yang sudah punah (korisultasi pribadi dengan Prof. Dr. S. Sartono).

Dalam periulisan ini dilakukan metode identifikasi dan determinasi, baik terhadap foto yang dilampirkan dalam laporan kerja Bidang Permuseuman Sejaráh dar Purbakala Kantor Wilayah Departemen Pendidikan dan Kebudayaan Propinsi Kalimantan Selatan maupun terhadap sisa binatang fosil yang sudah menjadi salah satu koleksi Pusat Penelitian Arkeologi Nasional seperti yany disebutkan di atas. Di samping itu dilakukan metode penelusuran data kepustakaan sebagai bahan pembanding.

\section{LOKASI TEMUAN}

Lokasi tempat ditemukan sisa-sisa Elephas yang dibahas dalam tulisan ini terletak di Desa Damsari, Kecamatán Tamban, Kabupaten Batola, Propinsi Kalimantan Selatan. Daerah tersebut sebenarnya merupakan daerah rawa, yang mulai dihuni oleh para transmigran, baik lokal maupun pendatang sejak tahun 1935. 
Sisa Elephas yang dibahas ini ditemukan dalam sebuah handil (terusan/saluran) Wonoasri, dengan jarak 600 meter dari sungai Tamban ke arah selatan. Lokasi temuan terletak sekitar 130 meter dari Handil Wonosari ke arah timur dan sudah masuk ke dalam wilayah Desa Koanda. Sisa-sisa elephas tersebut ditemukan oleh Haji Sulaiman ketika sedang membuat lubang galian untuk menanam pohon kelapa, pada kedalaman 2,5 meter.

Untuk mencapai lokasi penemuan hanya dapat dilakukan melalui jalan air. Kendaraan air yang dapat digunakan berupa kelotok, longboat, speedboat, atau kendaraan sejenisnya. Bila digunakan kelotok, dapat ditem:puh dalam waktu kurang lebih 1,5 jam pelayaran dari Banjarmasin (dermaga pasar Antasari), tetapi bila digunakan kendaraan air bermotor lainnya kurang dari 1,5 jam. Rute perjalanan yang harus ditempuh ialah dari Banjarmasin menuju ke barat daya menelusuri sungai Martapura, sungai Barito, kemudian Sungai Tamban Luar, Sungai Punggu II, dan sampai di Desa Damsari, yang keseluruhannya berjarak 9,5 kilometer.

\section{PEMERIAN}

Temuan sisa elephas dari.Tamban, seluruhnya berjumlah 21 potong. Keduapuluhsatu potong sisa elephas tersebut terdiri dari 11 potong fosil gigi, 1 potong tulang paha (panjang $105 \mathrm{~cm}, \varnothing 49 \mathrm{~cm}$ ), 1 potong tulang pengumpill (panjang $80 \mathrm{~cm}, \varnothing 9 \mathrm{~cm}$ ), 1 'tulang hasta (panjang $80 \mathrm{~cm}, \varnothing 9 \mathrm{~cm}$ ), 3 tulang rusuk (panjang $105 \mathrm{~cm}$, $\varnothing 3 \mathrm{~cm}$ ) dan 4 ruas tulang punggung (panjang $33 \mathrm{~cm}$, $\emptyset 10 \mathrm{~cm}$ ).

Fragmen gigi setelah direkonstruksi ternyata merupakan salah satu lammela (lempengan gigi) dari sebuah geraham elephas. Lammela tersebut berukuran panjang $88 \mathrm{~mm}$, lebar pada bagian pangkal gigi $55 \mathrm{~mm}$, pada bagian dekat mahkota gigi $46 \mathrm{~mm}$, tebal pada bagian pangkal gigi $21 \mathrm{~mm}$, dan tebal pada bagian dekat mahkota gigi 6,5 $\mathrm{mm}$. Lammela dari geraham Bangsa Proboscidea meru- 
pakan unsur penting. Dari permukaan mahkota geraham, baik yang sudah mengalami proses pengausan karena sering digunakan maupun yang belum mengalami proses pengausan, dapat diketahui dan ditentukan pada kedudukan aslinya. Selanjutnya dari jumlah lammela yarıg ada, para pakar dapat mengetahui dan menentukan jenis gajah seperti yang dapat dilihat dalam tabel di bawah ini.

$\begin{array}{llllllll}\text { 1. Elephas africanus } & \frac{3}{3}^{++} & \frac{6}{6} & \frac{7}{7} & \frac{7}{7} & \frac{8}{8-9} & \frac{10}{11}\end{array}$

2. Elephas planifrons $\quad \frac{3}{3} \quad \frac{6}{6} \quad \frac{7}{7} \quad \frac{7}{7} \quad \frac{8}{8-9} \quad \frac{10}{10-11}$

3. Elephas meridionalis $\frac{3}{3} \quad \frac{5-6}{5-6} \quad \frac{7-8}{7-8} \quad \frac{8-9}{8-9} \quad \frac{8-11}{9-11} \frac{10-14}{11-14}$

4. Elephas antiquus $\frac{3}{3} \quad \frac{5-7}{6-8} \frac{8-11}{9-11} \frac{9-12}{10-12} \frac{12-13}{12-13} \frac{15-20}{16-21}$

5. Elephas hysudricus $\frac{3}{3} \quad \frac{5-7}{7-9} \quad \frac{9-11}{9-11} \frac{9-12}{9-12} \frac{10-12}{12-13} \frac{13-17}{14-18}$

6. Elephas indicus $\frac{4}{4} \cdot \frac{8}{8} \quad \frac{12}{12} \frac{12-14}{12-14} \frac{16-18}{16-18} \frac{24}{24-27}$

7. Elephas primigenius $\frac{4}{4}-\frac{6-9}{6-9} \quad \frac{9-12}{9-12} \quad \frac{9-15}{9-15} \quad \frac{14-16}{14-16} \frac{18-27}{18-27}$

\section{Keterangan :}

$\mathrm{D}_{3_{+}^{+}}^{+}=$deciduous = gigi susu.

$\frac{3}{3}^{++}=$angka di atas menunjukkan jumlah lamella geraham rahang atas angka yang di bawah menunjukkan jumlah lamella geraham rahang bawah (Karl. A. van Zittel, 1925: 262).

Dalam tabel tersebut di atas dapat dilihat formula susunan lamella pada gigi susu kedua $\left(D_{2}\right)$, gigi susu ketiga $\left(D_{3}\right)$, gigi susu keempat $\left(D_{4}\right)$, geraham tetap perta- 
má $\left(M_{1}\right)$, geraham tetap kedua $\left(M_{2}\right)$, dan geraham ketiga $\left(M_{3}\right)$ yarıg dimiliki oleh beberapa jenis elephas. Berdasarkan formula tersebut para pakar paleontologi dapat merieritukan jenis-jenis elephas, dengan menperhatikan, mengukur, dan menghiturig jumlah lamella geraham baik dalam keadaan utuh maupun berupa fragmen. Misalnya analisis yang pernah dilakukanoleh Prof. Dr. S. Sartono terhadap sisa biriatang fosil, yang terdiri dari sepotong fargmen geraham. Setelah diukur, dan dihitung lamella yang utuh terdiri dari 5 potong termasuk dengan talonid (calon lamella), kemudian diketahui fragmen gerahami tersebut berasal dari individu yang dikenal sebagai Stegodon Timorensis Sartono (Sartono, 1973). Jenis tersebut merupakan salah satu jenisba yang sudah punah yang sama jenisnya dengan elephas planifrons seperti dalam tabel tersebut di atas.

Setelah diperoleh gambaran tentang jenis-jenis elephas berdasarkan formula lamella geraham-geraham elephas yang bersangkutan, maka pakar dapat membuat rekonstruksi bentuk badan gajah dan menyusun evolusi perkembangan Bangsa Proboscidea yang dimulai sejak zaman Eosen. Dengan ditemukannya sisa elephas di Tamban maka wilayah persebaran elephas di Indonesia maupun di Asia Tenggara makin bertambah banyak.

Sisa elephas dari Tamban lainnya yang pada saat ini juga menjadi salah satu koleksi Pusat Penelitian Arkeologi Nasional adalah fragmen sebuah ruas tulang punggung (Vertebrae Thoraxia). Ruas tulang punggung tersebut besarnya adalah sebagai berikut. Panjang corpus (badan ruas tulang punggung) $77 \mathrm{~mm}$, lebar corpus $98 \mathrm{~mm}$, panjang spina neurosa (tajuk duri) $195 \mathrm{~mm}$, lebar pangkal spina $168 \mathrm{~mm}$, lebar ujung atas spina $21 \mathrm{~mm}$, tebal spina $30 \mathrm{~mm}$. Dilihat bentuknya dan setelah dibandingkan dengan gambar-gambar dalam literatur-literatur yang ada (von Zittel, 1925; de Boer en Sondaar, 1979; Cornivall, 1956), fragmen ruas tulang punggung elephas 
tersebut menempati urutan ke 17 atau ke-18 dalam struktur pada tulang punggung seekor elephas.

\section{PEMBAHASAN}

Dalam beberapa catatan yang ada dan setelah disesuaikan dengan temuan sisa elephas yang telah dibahas di bagian depan, sekalipun temuan ituhanya diwakili oleh 3 potong tulang rusuk, 1 potong tulang paha, 1 potong tulang pengumpil, 1 potong tulang hasta, 4 potong ruas tulang punggung dan 11 potong fragmen gigi, dapat dipastikan bahwa sisa binatang fosil tersebut adalah Elephas Maximus, Suku Elephas, Marga Elephantidae, Bangsa Proboscidea, sama seperti sisa-sisa sejenisnya yang telah ditemukan antara lain di Jawa, Bangka, Biliton, dan Sumatera.

Dalam catatan-catatan lama disebutkan bahwa jenis gajah seperti yang dikenal sekarang, daerah hidupnya di hutan-hutan lamping gunung, dan kadang-kadang mereka turun ke padang-padang rumput yang diselang-seling belukar untuk mencari makanan. Mereka juga tidak takut air, karena bagaimana diketahui air sangat diperlukan oleh semua makhluk hidup.

Keadaan lingkungan tempat sisa Elephas maximus ditemukan di Tamban, pada saat ini adalah tanah rawa. Apakah pada waktu binatang tersebut hidup sudah ada rawa? Mengapa sisa-sisa binatang tersebut ada di sana, kalau rawa tersebut telah sejak lama terjadi? Hal tersebut tak dapat dipungkiri bila dilihat keadaan geomorfologi Kalimantan Indonesia pada saat ini. Kalimantan Selatan sebagian besar terdiri dari tanah rawa. Bila dilihat dari kenyataan tersebut di atas maka tidak mungkin jenis elephas ini hidup di tanah rawa. Dengan kata lain dapat dikatakan bahwa pada saat binatang tersebut hidup, daerah tersebut merupakan tanah dataran rendah yang diselang-seling dengan belukar sebagai tempat mencari makanan. 
Di Indonesia jenis Elephas maximus hanya hidup di Pulau Sumatera. Populasinya belum dihitung secara pasti (Carter, 1978: 49). Suwedi Montana memberikan informasi bahwa gajah yang hidup di Pulau Kalimantan hanya terdapat di ujung paling utara, yaitu di Kinibalu. Informasi tersebut sesuai dengan berita yang terdapat dalam L.E.M. de Boer en P.Y. Sondaar (1979: 3, Fig. 2). Sebaliknya S. Sartono masih memberikan keragu-raguan dalam jawaban tentang kehidupan, gajah di Kalimantan Utara itu apakah benar-benar hidup di sana atau datang dari luar, walaupun di sana pernah ada catatan tentang penemuan kerabat dekat Elephas maximus, yaitu Stegolophodon latidens (Sartono, 1973: 4, Fig. 1). Meskipun demikian tidak dapat dibantah bahwa jenis Elephas maximus pernah hidup di Pulau Kalimantan yang sisa-sisanya ditemukan di Tamban. Dengan adanya bukti tersebut maka timbul pertanyaan, bagaimana gajah tersebut dapat sampai di tempat itu, dengan cara apa, bilamana, dan melalui jalan mana?

Seperti diketahui bahwa di muka bumi ini pernah terjadi jaman glasiasi dan deglasiasi yang silih berganti, $\mathrm{Di}$ Indonesia juga pernah mengalami akibatnya danakibat jaman glasiasi terakhir di wilayah Indonesia terjadi pada kala Plestosen akhir. Akibatnya di beberapa tempat muncul jembatan-jembatan tanah (land-bridge) yang saling berhubungan seperti di Pulau-pulau Sumatera, Jawa, dan Kalimantan (Heekeren, 1957: 7; 'Soejono et al., 1984). Pada masa itu diperkirakan Suku Elephas menyeberang dari Sumatera ke Kalimantan, melalui jembatan tanah di Bangka, Biliton, Singkep. Ada juga kemungkinan lain bahwa Suku Elephas tersebut menyeberang dari daratan Asia melalui jalur Formosa (Taiwan), Filipina, dan sampai di Kalimantan (Sartono, 1987).

Gajah sekarang yang masih hidup, baik di Benua Afrika mauun di Benua Asia diketahui bahwa baik gajah Afrika maupun gajah Asia itu berasal dari Marga dan Suku yang sama, namun mereka memiliki 
bentuk dan nama yang berbeda. Gajah Afrika memiliki bentuk badan yang lebih besar dibandingkan dengan kerabatnya dari Asia (India). Ciri-ciri dan perbedaan yang menyolok dari kedua jenis gajah ini ialah terletak pada: (1) telinga gajah Afrika lebih besar dan lebar; (2) ujung belalai gajah Afrika bercabang; (3) jari kaki belakang gajah Afrika berjumlah 3 buah, jari kaki belakang gajah India (Asia) berjumlah 4 buah; (4) bentuk badan gajah Afrika secara keseluruhan lebih besar (Kresno Yulianto Sukardi, 1984); (5) susunan ruas tulang punggung gajah Afrika sama seperti konstruksi bentangan jembatan berbentuk cekung, sedangkan susunan ruas tulang punggung gajah India (Asia) sama seperti konstruksi bentangan jembatan berbentuk cembung (de Boer en Sondaar, 1979, (6) nama yang dikenal Paleontologi maupun Biologi, gajah Afrika dikenal dengan nama Laxodonta Africana, sedangkan gajah India (Asia) dikenal dengan nama Elephas maximus yang di Indonesia dikenal dengan sebutan Elephas maximus Sumateraensis.

Bila diamati kondisi dan proses fosilisasi pada sisa elephas dari Tamban ternyata belum mencapai proses fosilisasi penuh, sehingga diperkirakan umur dari Elephas Tamban adalah Kala Plestosen Akhir, atau kurang lebih 10.000 tahun yang lalu (Konsultasi pribadi dengan Prof. Dr. S. Sartono). Perkiraan tersebut didasarkan pada pengarnatan megaskopis terhadap sisa elephas Tamban yang belum memperlihatkan matrik, baik pada fragmen geraham maupun pada fragmen ruas tulang punggung. Hal tersebut sesuai dengan keletakannya, yaitu pada dataran rendah, sekitar Sungai Barito yang menurut Bemmelen terbentuk pada Kala Plestosen (Bemmelen, 1970: 358). Dengan data tersebut S. Sartono berpendapat bahwa jenis tersebut tidak lebih tua dari Kala Plestosen Akhir atau sekitar 10.000 tahun lalu. 


\section{KEPUSTAKAAN}

Bemmelen, R.W. van. 1970. The Geology of Indonesia. Vol. IA. Martinus Nijhoff/ The Hague.

Boer, L.E.M. de en Sondaar, P.Y. 1979. "De Evolutie van de Olifantachtigen. Museologia, No. 12 Vol. VI.

Heekeren, H.R. van. 1957. "The Stone Age of Indonesia." Verhandelingen KITLV, XXI. 's-Gravenhage.

Sukardi, Kresno Yulianto. 1984. Fauna Pada Relief Karmawibhangga Candi Borobudur. Universitas Indonesia, Jakarta.

Sartono, S. 1973. "On An Additional Stegodon Timorensis Sartono." Geological Survey of Indonesia, Vol. 5.

Sartono, S. 1987. "Migrasi Manusia Plestosen Indonesia: kaitannya dengan tektonik lempeng." Geologi Kuarter dan Lingkungan Hidup. Publikasi khusus No. 7.

Soejono. R.P. et. al., 1984. Sejarah Nasional Indonesia I. Departemen Pendidikan dan Kebudayaan. PN. Balai Pustaka, Jakarta.

Veevers, W. Carter. 1978. Mamalia Darat Indonesia. PT. Intermasa, Jakarta.

Zittel, Karl. A. van. Text-book of Palaeontology. Vol. III. Mamalia. Translated by Charles R. Eastman. Macmillan and Co. Ltd., St. Martins Street, London.

Bidang Muskala Kan. Wil. Depdikbud Prop. Kalsel. 1987. Temuan sisa binatang fosil di Kecamatan Tamban, Kabupaten Batala (Kalimantan Selatan). 


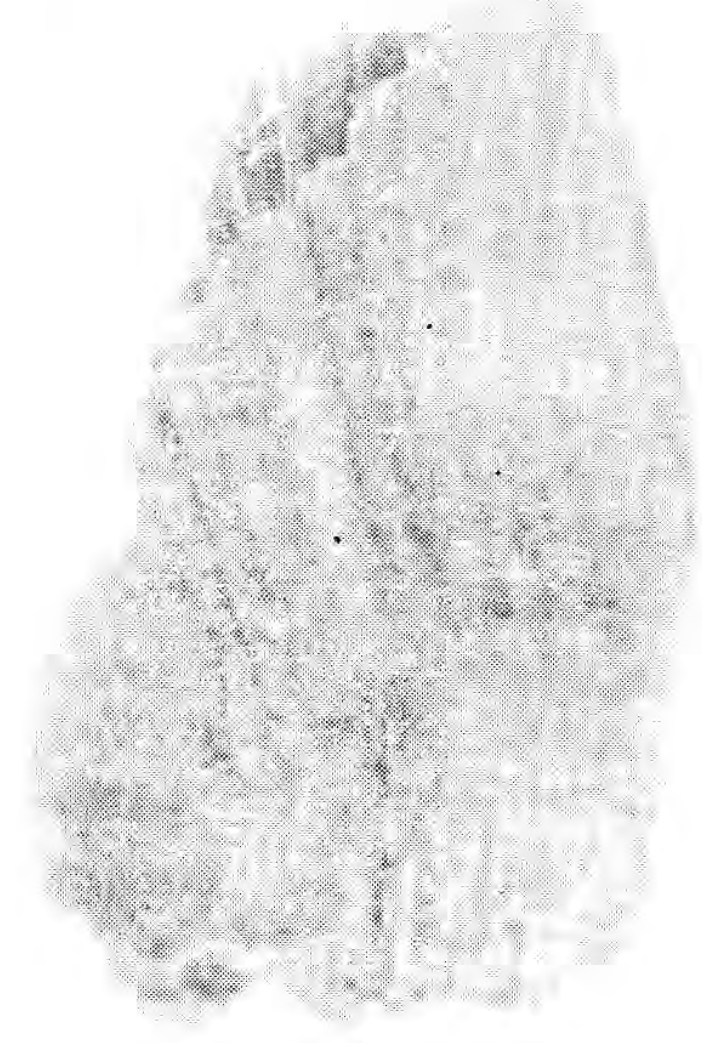

1

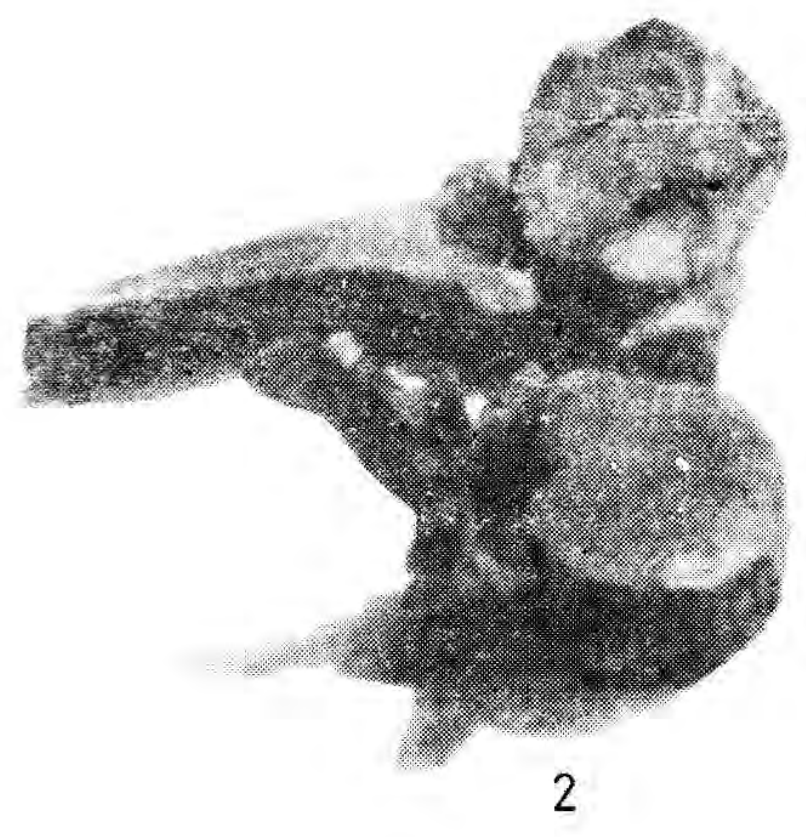

3

Fragmen gigi geraham dan tulang-tulang elephas (gajah) Tamban, Kalimantan Selatan :

1. Fragmen gigi geraham.

2. Ruas tulang belakang.

3. Tulang paha. 